\title{
Managing nickel metals in Agriculture contaminated soil into macrocyclic complex
}

\author{
Sangeeta Sahu \\ Department of Applied Chemistry, Bhilai Institute of Technology, Kendri, \\ New Raipur-493661, Chhattisgarh, INDIA
}

\begin{abstract}
Consumer demand for better quality produce is increasing. Some metals are not desirable in agriculture because they may harm the environment or humans. Because of this, the concentrations of metals in soils and foods should be regularly monitored. This brochure tells why should be concerned about metals in the farm soil and farm produce and how to manage the situation so that it does not become a problem.

This paper describes synthesis and characterization of macro cyclic complexes of nickel (II) derived from diethylenetriamine. The diethylenetriamine has been condensed with dichloromethane in presence of a metalion in different molar ratios as mentioned in their synthesis. This paper deals with short review and to study the heavy metals (Ni) present in Agriculture contaminated soil.

Keywords: Contaminated soil, Macro cyclic ligand, Macro cyclic complex, synthesis, spectroscopy, catalyst.
\end{abstract}

\section{INTRODUCTION}

In this paper an attempt is made to discuss studies in relation with heavy metal like $\mathrm{Ni}$, its source, effect on health and its physio-chemical property

The soil generally have low $\mathrm{pH}$, low organic content and low clay content and deficient in Nitrogen, phosphorous, calcium and magnesium. In order to maintain or increase the current level of levels of agricultural production, a variety of additives, such as fertilizers must be added to the deficient soils. Without these additives, crops yields rapidly reduce to low levels. Unfortunately, these soil additives can be contaminated with metals that can have negative effects on crops on quality and quantity.

Today, much more is known about the health effects on human being of Nickel metals. Exposure to metals has been linked with developmental retardation, various cancers, kidney damage, even death in some instance of exposure to very high concentration.

In view of the importance of the macro cyclic chemistry, the Nickel (II) complexes of azamacrocycles were synthesized. Template condensation of chlorocarbons with in presence of $\mathrm{Ni}$ (II) to yield a new macro cycle in which additional metal ions are incorporated in separate rings [1]. The macro cyclic ligands and their complexes have been characterized by elemental analysis, molecular weight determination, conductance, IR and NMR spectral studies. The ligands and their complexes have been used as catalyst in many industries.

\section{MATERIALS AND METHODS}

There are several approaches to managing metal Inputs and uptake in agriculture:

\subsection{Reducing inputs of additives to soil:}

The relative danger of adding various additives to soil due to their typical level of metal contamination. You need to be aware of metal impurities in these products and should use those with the lowest concentrations of metals that still meet your crops nutrient needs.

\subsection{Growing suitable crops:}

If metal concentrations in the soil are lower than the investigation levels, then they are unlikely to have been contaminated by metals and therefore it should not experience any problems growing crops. If however, the concentrations of metals in the soil exceed the investigation levels, then the soil may have had additional metals added to it and it could be approaching the concentrations that cause harmful effects on some crops.

\subsection{Enhancing soil conditions:}

High acidity (low $\mathrm{pH}$ ) increases the toxicity of metals in soils. The addition of lime to acid soils ( $\mathrm{pH}$ less than 7) will greatly reduce the release of metals from soil and therefore reduce the uptake by plants and animals 
Managing nickel metals in Agriculture contaminated soil into macrocyclic complex

\subsection{Land under cultivation:}

Land under cultivation effectively increases the mass of soil to which the soil additive is being added and this decreases the concentrations of added metals

\subsection{Synthesis of the Nickel (II) Complex of 1, 4, 7, 9, 12, 15-hexaazacyclohexadecane (HACH) from the contaminated soil:}

In view of the importance of macro cyclic chemistry' the $\mathrm{Ni}$ (II) complexes of new categories of aza macro cyclic were synthesized. Template condensation of chloro carbon such as dichloromethane with tetraamine such as diethylenetriamine in presence of $\mathrm{Ni}$ (II) yield the corresponding metal complex of the following macro cyclic legend - 1,4,7,9,12,15-hexaazacyclohexadecane (HACH) [2].

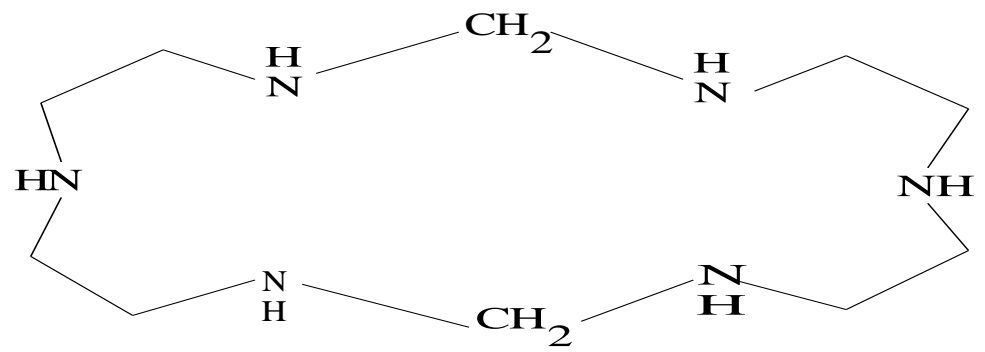

Figure 1. Macro cyclic legend - 1, 4, 7, 9, 12, 15-hexaazacyclohexadecane (HACH)

A mixture contain nickel hydroxide ( $6.00 \mathrm{~g}, 64.70 \mathrm{mmole})$, diethylenetriamine ( $6.68 \mathrm{~g}, 64.75 \mathrm{mmole})$ and dichloromethane $(5.50 \mathrm{~g}, 64.76 \mathrm{mmole})$ was prepared in $200 \mathrm{ml}$ butanol. A light green precipitate formed in the mixture turned milky green after shaking for 2 min. The resulting milky green mixture was further refluxed for $2 \mathrm{~h}$, during which time it changed to a violet solution consisting a green precipitate. The content was then cooled, stirred for about $10 \mathrm{~min}$ with $80 \mathrm{ml}$ of water and filtered. The light green precipitate was rejected and aqueous violet layer of the filtrate containing macro cyclic product was separated from the non-aqueous coloureless layer. Concentration and refrigeration of aqueous layer yielded reddish-violet crystals of $\left[\mathrm{Ni}_{2}(\mathrm{HACH})\left(\mathrm{H}_{2} \mathrm{O}\right)_{6}\right] \mathrm{Cl}_{4} \cdot 10 \mathrm{H}_{2} \mathrm{O}$. The crude crystals were washed with methanol followed by acetone to obtain analytically pure product, yield $4.62 \mathrm{~g}$.

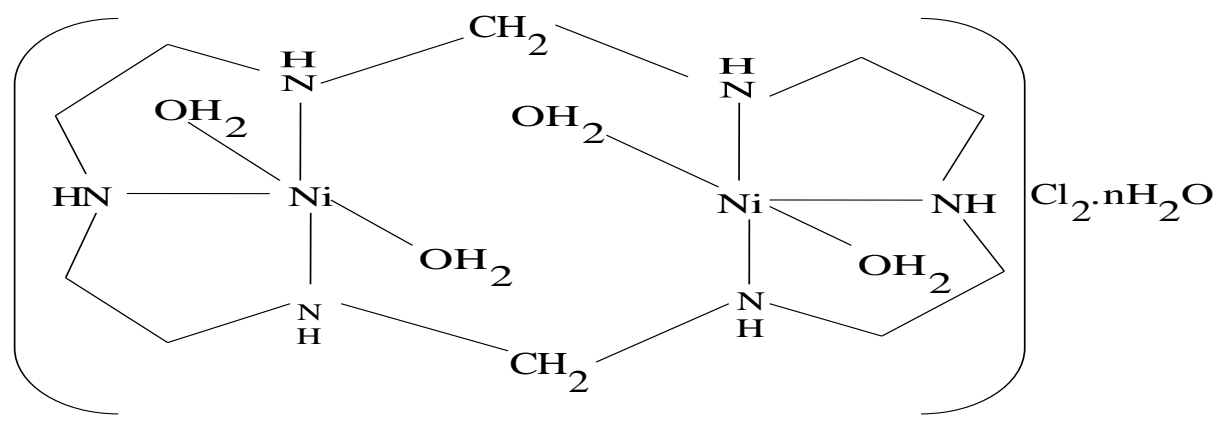

Figure 2. Nickel (II) Complex of 1, 4, 7, 9, 12, 15-hexaazacyclohexadecane (HACH)

\section{RESULT AND DISCUSSION}

The template condensation of diethylenetriamine with chloroCarbon in presence of nickel hydroxide yields dinuclear complexes [3-5]. As expected, structurally similar macrocycles 1, 4, 7, 9, 12, 15hexaazacyclohexadecane $(\mathrm{HACH})$ are generated in template condensation of diethylenetriamine with dichloromethane and chloroform in presence of nickel hydroxide in their equimolar mixture. Each macromolecule HACH incorporates two metal ions in its cavity. 


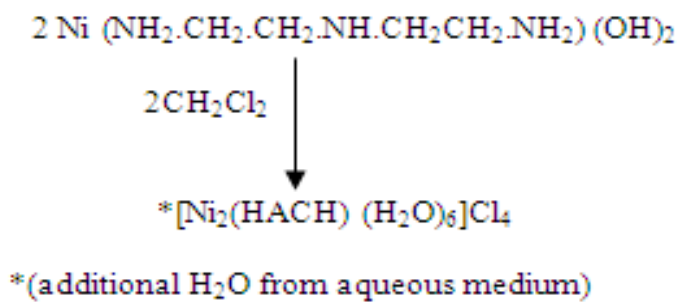

These complexes were characterized on the basis of elemental analysis, conductivity measurement, mass spectra, infrared and proton nuclear magnetic resonance spectral studies. The results of elemental analyses reported in the (Table 1.1) indicate the stoichiometry which is in agreement with the formulation given. Evidence for cyclization is demonstrated by the absence of infrared absorption bands that may be attributed to either free or coordinated $\mathrm{NH}_{2}$ groups [5-7].

\subsection{Chemical analysis:}

Microanalysis for carbon, hydrogen and nitrogen were carried out at the regional sophisticated instrumentation centre, central drug research institute (CDRI) Lucknow.For obtaining nickel contents of the complexes, they were decomposed by strong heating in the presence of fusion mixture. Concentrated $\mathrm{H}_{2} \mathrm{SO}_{4} \mathrm{was}$ added, and the content was boiled, a pinch of urea was introduced after white fumes appeared to remove any oxide of nitrogen. After cooling the completely decomposed matter, a small amount of water added and the solution filtered. The metal content was determined by EDTA [8] titration The ionizable chloride ions in the compounds were determined by conductometric titration using $0.01 \mathrm{M}$ ligand /complex and $0.1 \mathrm{M} \mathrm{AgNO}_{3}$ solution. (Table 1.1)

Table 1.1: Analytical and physical data of the Nickel (II) Complex of 1, 4, 7, 9, 12,15-hexaazacyclohexadecane $(\mathrm{HACH}) \mathrm{Macrocyclic}$ Compounds derived from diethylenetetriamine:

\begin{tabular}{|c|c|c|c|c|c|c|c|c|c|}
\hline \multirow[t]{2}{*}{ Compound } & \multirow{2}{*}{$\begin{array}{l}\text { Colour } \\
\text { (colour } \\
\text { at D.P.) }\end{array}$} & \multirow{2}{*}{$\begin{array}{l}\text { Yield } \\
(\%), \\
\text { (D.P. } \\
\text { v } \\
\text { M.P.) } \\
\text { ("C) }\end{array}$} & \multirow{2}{*}{$\begin{array}{l}\text { Conductivity } \\
\left(\mathrm{ohm}^{-1} \mathrm{~cm}^{2}\right. \\
\left.\mathrm{mol}^{-1}\right)\end{array}$} & \multicolumn{5}{|c|}{$\%$ Found (Calculated) } & \multirow{2}{*}{$\begin{array}{l}\text { Mol. } \\
\text { wt. } \\
\text { Found } \\
\text { (Calcula } \\
\text { ted) }\end{array}$} \\
\hline & & & & $\mathrm{C}$ & $\mathrm{H}$ & $\mathrm{N}$ & $\mathrm{Ni}$ & $\mathrm{Cl}$ & \\
\hline $\begin{array}{l}{\left[\mathrm{Ni}(\mathrm{HACH})\left(\mathrm{H}_{2} \mathrm{O}\right)_{6}\right]} \\
\mathrm{Cl}_{4} \cdot 10 \mathrm{H}_{2} \mathrm{O} \\
\mathrm{Ni}_{2} \mathrm{C}_{10} \mathrm{H}_{58} \mathrm{~N}_{5} \mathrm{O}_{16} \\
\mathrm{Cl}_{4}\end{array}$ & $\begin{array}{l}\text { Reddish } \\
\text { violet } \\
\text { (black) }\end{array}$ & $\begin{array}{l}18.36 \\
(244)\end{array}$ & 450 & $\begin{array}{l}15.50 \\
(15.44)\end{array}$ & $\begin{array}{l}7.55 \\
(7.53)\end{array}$ & $\begin{array}{l}10.78 \\
(10.81)\end{array}$ & $\begin{array}{l}15.04 \\
(15.09)\end{array}$ & $\begin{array}{l}18.29 \\
(18.23)\end{array}$ & $(778.0)$ \\
\hline
\end{tabular}

\subsection{Physical measurements:}

Conductivity data of the complex was recorded using their $0.01 \mathrm{M}$ aqueous solution, with the help of a DDR Conductivity meter type 304. A Jeol D-300 (El/Cl) spectrometer was used for obtaining the mass spectra of the ligand hydrochlorides of low molecular weight. Infrared spectra in the range $4000-250 \mathrm{~cm}^{-1}$ were recorded by Perkin Elmer infrared spectrometer in $\mathrm{KBr}$ pellets. FTIR spectra of a number of compound were recorded by Shimadzu $8201 \mathrm{PC}\left(4000-350 \mathrm{~cm}^{-1}\right)$ infrared spectrophotometer. The pmr spectra were taken in $\mathrm{D}_{2} \mathrm{O}$ solution and recorded on bruker DRX300 (300 MHz. PT NMR) using tetra methylsilane as an internal standard [9]. (Table 1.1)

\subsection{Infrared spectra: HACH System}

The presence of coordinated water molecules in the nickel-HACH complex is indicated by bands at 3300 (strong very sharp), 3250 (very strong, sharp), 700 (very strong, sharp), 700 (very weak, sharp), 600 (medium, sharp) and $580 \mathrm{~cm}^{-1}$ (very weak, sharp) assigned to $\mathrm{O}-\mathrm{H}$ asymmetric stretching, rocking, wagging and twisting vibration, respectively. A medium but sharp band at $500 \mathrm{~cm}^{-1}$ is due to $v(\mathrm{Ni}-\mathrm{O})$. The characteristics 
Managing nickel metals in Agriculture contaminated soil into macrocyclic complex

bands at 2925 (strong, sharp), 2865 (very weak, very sharp) and $1478 \mathrm{~cm}^{-1}$ (very weak, very sharp) are attributed to $\mathrm{C}-\mathrm{H}$ asymmetric, symmetric stretching stretching and scissoring vibrations, respectively. A very weak band at $450 \mathrm{~cm}^{-1}$ indicates that the metal is coordinated to ligand through the $\mathrm{N}$-atoms [10]. (Table 1.2)

Table 1.2 Important IR Bands of the Macrocyclic Compound Derived from triethylenetetramine

\begin{tabular}{|c|c|}
\hline Compound & $\begin{array}{l}\text { IR Bands }\left(\mathrm{cm}^{-1}\right) \text { Table 1.3: for Important IR Bands of the Macrocyclic } \\
\text { Compounds Derived from diethylenetriamine }\end{array}$ \\
\hline $\begin{array}{l}\left.\mathrm{Ni}(\mathrm{HACH})\left(\mathrm{H}_{2} \mathrm{O}\right)_{6}\right] \mathrm{Cl}_{4} \cdot 10 \mathrm{H}_{2} \mathrm{O} \\
\mathrm{Ni}_{2} \mathrm{C}_{10} \mathrm{H}_{58} \mathrm{~N}_{5} \mathrm{O}_{16} \\
\mathrm{Cl}_{4}\end{array}$ & 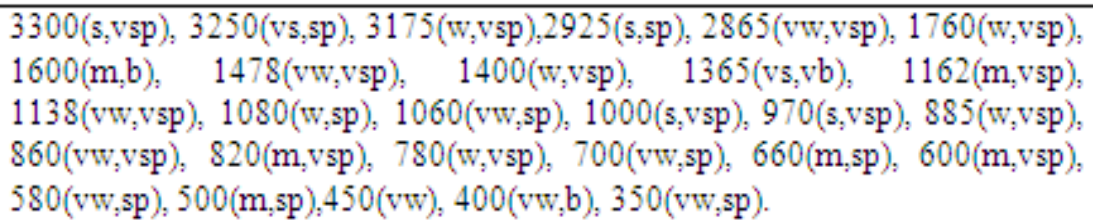 \\
\hline
\end{tabular}

*Abbreviations Used: $b=$ broad, $d=$ doublet, $m=$ medium, $s=$ strong, $s h=$ shoulder, $s p=$ sharp, $v b=$ very broad, vs. $=$ very strong, $\mathrm{vsp}=$ very sharp, $\mathrm{vw}=$ very weak, $\mathrm{w}=$ weak

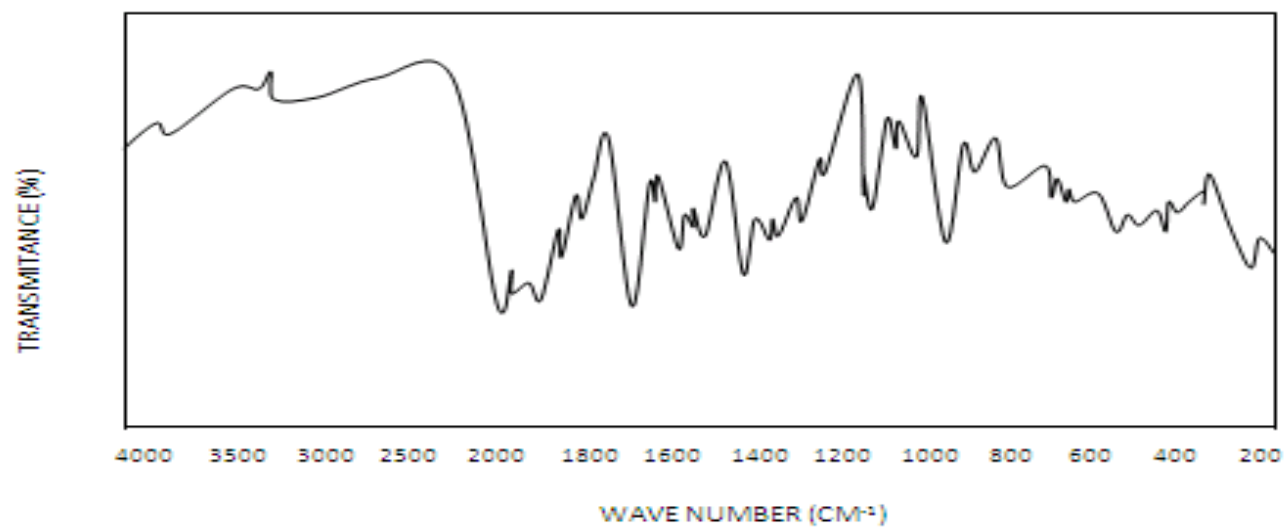

Figure 3: IR Spectra of $\left.\mathrm{Ni}(\mathrm{HACH})\left(\mathrm{H}_{2} \mathrm{O}\right)_{6}\right] \mathrm{Cl}_{4} \cdot 10 \mathrm{H}_{2} \mathrm{O}$ or $\mathrm{Ni}_{2} \mathrm{C}_{10} \mathrm{H}_{58} \mathrm{~N}_{6} \mathrm{O}_{16} \mathrm{Cl}_{4}$

\subsection{Nuclear magnetic resonance spectra:}

HACH System

The pmr spectrum of HACH hydrochloride can be resolved into three distinct regions due to $\mathrm{NH}_{2}{ }^{+}$and monequivalent $\mathrm{CH}_{2}$ proton.It shows a broad singlet at $4.98 \mathrm{ppm}$ assigned to $\mathrm{NH}_{2}{ }^{+}$resonances. The remaining two signals for monequivalent $\mathrm{CH}_{2}$ protons are broad triplets centred at 3.46 and $3.54 \mathrm{ppm}$ [11].

\subsection{Mass Spectra:}

The determination of molecular weights of $\left[\mathrm{Ni}(\mathrm{HACH})\left(\mathrm{H}_{2} \mathrm{O}\right)_{6}\right] \mathrm{Cl}_{4} \cdot 10 \mathrm{H}_{2} \mathrm{O}$ by FABMS has been very useful in completing their characterization. the highest mass peaks found in the spectrum occurs at $\mathrm{m} / \mathrm{z}$ values close to their molecular ion (table 1.1). The slightly low $\mathrm{m} / \mathrm{z}$ values in $\mathrm{HACH}$ systems may be associated with the mass lost $(\mathrm{H})$ due to fragmentation of the molecular ion [12-13].

\subsection{Solubility, Conductivity and Other Data:}

The compounds are highly soluble in water and generally in polar solvents like ethanol, methanol, DMF, DMSO etc. The molecular conductivity of the complexes and the number of ionizable chloride ion in all macrocyclic molecules recorded in the (Table 1.1) are in support of ionic structures. [Ni (HACH) $\left.\left(\mathrm{H}_{2} \mathrm{O}\right)_{6}\right] \mathrm{Cl}_{4} \cdot 10 \mathrm{H}_{2} \mathrm{O}$ electrolytes exhibiting molar conductance in the 778 range $\left(\mathrm{ohm}^{-1} \mathrm{~cm}^{2} \mathrm{~mol}^{-1}\right)$. The nickel complexes of macrocyclic are reddish-violet. The complexes are thermally stable and decompose above $200^{\circ} \mathrm{C}$ [14-15]. 


\section{CONCLUSION}

According to the result of this study, Nickel metal ions present in contaminated soil can be isolated and treated with equimolar amount of diethylenetriamine and dichloromethane, macro cyclic complexes are formed. The macro cyclic ligands and their complexes have been characterized by elemental analysis, molecular weight determination, conductance, IR and NMR spectral studies. The spectral data suggested Hexa coordinated state for Nickel, its geometry is outer orbit octa hedral.Conductivity data suggests that they behave as electrolytes. The formulation of the complexes has been established on the basis of chemical composition. The ligand and their complexes have been used as catalyst in many industries. This is used as hydrogenation catalyst. Nahata catalyst which acts as an efficient reusable heterogeneous catalyst. This catalyst use in drug discovery and drug development.

\section{REFERENCES}

[1] Renfrew R.W., Jamison R.S. and Weatherbum D.C., Inorg. Chem; 18, 1584 (1979)

[2] Schwindinger W.F., Fawett T.G., Lalancctte, R.A.Potenza, J.A.and Schugar H.Inorg. Chem; 19, 1379 (1980).

[3] Aly A.A.M. and Shahbasy M.E., Synth. React. Inorg. Met. Org. Chem; 17,257 (1987).

[4] Folting K.Strieb W.E., Caulton, K.G.Poncelet O. and Bubert Pfal, zgraf L.G., Polyhedron 10, 1639 (1991).

[4] Cayton R.H., Chisholm M.H., Davidson E.R., Distasi V.F., Pig Du and Huffman J.C., Inorg. Chem; 30,1020 (1991)

[5] Gale P.A., Coord. Chem. Rev; 103, 4419(2003).

[6] Martinez, Mauez and Sancenon F., Chem. Rev; 103, 4419 (2003).

[7] Fillaut J.L., Andtries J., Toupet L., and Des Vergne J.P., Chem. Commun; 2924 (2005).

[8] Fleischer E.B., Sklar L., Kendall Torry A., Tasken P.A., and Taylor F.B., Inorg. Nucl. Chem. Lett; 9,106(1973),

[9] Tocher, D.A., Pal and Datta D., Inorg. Chem; 42, 7704(2003).

[10] Costero A.M.Banuls M.J., Aurell M.J.Ward M.D.and Arget S., Tetrahedron 60, 9471 (2006).

[11] Banerjee S.R., and Schaffer P., Babich J.W., Valliant J.F. and Zubieta J., Dalton Trans. 3886 (2005)

[12] Garino C.,Ghiani S.,Gobetto R.,Nervi C. Sulassa L., Ancarani V., Neyroz P., Franklin L.,Ross J.B.A. and Seibert E., Inorg. Chem; 44, 3875 (2005).

[13] Christou, G., Perlepes S.P., Libby E., Folting, K., Huffmann J.C., Webb R., J. and Hendrickson D.N., Inorg. Chem; 29 , 3657 (1990)

[14] Sun L., Hammarstorm, L., Akermark, B. and Styring S., Chem. Soc. Rev; 30, 36 (2001).

[15] McFarland S.A., Magde D., and Finney N.S., Inorg. Chem; 44, 4066 (2005). 